\title{
The risk of ischemic stroke in patients with head and neck cancer undergoing radiotherapy: a nationwide population-based ecological study
}

\author{
H.J. Han ${ }^{1,3}$ and H. Jang',4* \\ ${ }^{1}$ Department of Neurosurgery and ${ }^{2}$ Department of Radiation Oncology, Dongguk University Gyeongju Hospital, \\ Gyeongju, South Korea \\ ${ }^{3}$ Department of Preventive Medicine and ${ }^{4}$ Department of Radiation Oncology, Dongguk University College of \\ Medicine, Gyeongju, South Korea
}

\section{- Original article}

*Corresponding author:
Hyunsoo Jang M.D., Ph.D.,
E-mail:
$\quad$ opencagejhs@gmail.com
Revised: November 2020
Accepted: May 2021
Int. J. Radiat. Res., October 2021;
19(4): 829-834
DOI: 10.29242/ijrr.19.4.829

\begin{abstract}
Background: The whole neck is often included in the radiation therapy (RT) field of head and neck cancer (HNC), and carotid vessels of the neck may be affected by radiation in a manner that increases the risk of ischemic stroke (IS). In the present study, we analyzed the relationship between RT for HNC and subsequent IS using a database managed by the Health Insurance Review \& Assessment Service. Materials and Methods: A public insurance system was used to identify a nationwide cohort of patients diagnosed with HNC that underwent RT. The incidence of IS after RT was determined up to the end of December 2018, and associated risks were analyzed. In addition, patients that underwent frequent elective neck irradiation as determined by disease classification or less frequent elective neck irradiation were allocated to groups A and B, respectively. Results: 12,079 HNC patients that received RT between 2010 and 2014 were identified. 472 (3.9\%) of the subjects experienced IS and incidence rates were $>5 \%$ for hypopharyngeal cancer and supraglottic cancer. The incidence of IS was $5.4 \%$ in patients $>60$ years and $2.2 \%$ in patients $<60$ years (relative risk (RR) 2.59 ). In addition, the incidence of IS was greater in group A than in group B (RR 1.29), and in men than in women (RR 1.33). Conclusion: When performing extensive RT involving the whole neck in older men, close follow-up and prophylactic medication should be considered to prevent IS.
\end{abstract}

\section{Keywords: Radiotherapy, head and neck cancer, ischemic stroke}

\section{INTRODUCTION}

Head and neck cancer (HNC) accounts for about $3 \%$ of all cancers. Approximately 53,000 Americans develop head and neck cancer annually and 10,800 succumb to the disease (1). HNC more often affects individuals over 50 years old, and is usually associated with environmental and lifestyle risk factors, such as smoking and alcohol and certain strains of viruses (e.g., papillomaviruses) (1-3). HNC can be treated surgically or by radiation therapy (RT) or chemotherapy, depending on pathology, location, and stage, and in some cases, combined treatment may be used. HNC is highly curable if detected early, when it is usually treated surgically. RT may be widely applied to lesions that are difficult to access surgically or likely to cause cosmetic problems. Metastasis to neck lymph nodes is common in HNC, and thus, whole neck is often included in RT fields $(4,5)$. However, even after successful definitive therapy, quality of life may be compromised in HNC survivors because of treatment-related complications, and cerebrovascular disease is one such complication $(6,7)$.

Stroke is a common neurological complication of cancer, and substantially 
increases patient burden. The occurrence of stroke in cancer patients has been attributed to many risk factors, such as tumor-related disorders, coagulopathy, infection, complications of cancer treatment, and paraneoplastic effects. Some have reported how ionizing radiation damages blood vessels and have raised concerns about the potential risk of ischemic stroke (IS) after RT (8-11). However, it is still uncertain whether RT increases the risk of IS more so than other treatments. Some have reported increases in the incidence of IS after RT, whereas others have not $(8,11)$. However, RT is known to be associated with the development of IS in patients that develop a vascular disease such as stenosis or vasculitis after RT. Since the first histological reports were issued on vascular damage caused by ionizing radiation, animal and human studies have focused on determining the acute and chronic effects of ionizing radiation on the structures of cerebrovascular vessels.(12-14) Small blood vessels without a muscle layer or outer membrane are highly susceptible to endothelial cell damage by ionizing radiation, which causes thrombosis and ischemia of the microvascular layer and leads to radiation necrosis $(8,15-18)$.

Some authors have reported IS is associated with carotid artery stenosis, $(16,19-21)$ and that RT thickens the carotid wall and increases the risk of carotid artery stenosis. It has also been reported carotid plaque scores are nine times higher in patients that have undergone RT(22). These findings indicate the risk of IS is likely to be greater in HNC patients who undergo wide neck irradiation. The present study was performed using the database managed by the Health Insurance Review \& Assessment Service (HIRA) on HNC patients who had received RT. The incidences of IS were analyzed with respect to RT range, and in addition, we sought to identify the risk factors of IS in HNC patients. There are already some papers presenting the risk of IS by neck irradiation, but the verification was difficult due to the low incidence of HNC. Through this study, it is expected that the correlation between neck irradiation and IS can be confirmed.

\section{MATERIALS AND METHODS}

South Korea has a public insurance system called the National Health Insurance (NHI) system, and data such as gender, age, diagnosis, prescription, and procedures are stored in the Health Insurance Review \& Assessment Service (HIRA) database. In the present study, a nationwide cohort was obtained from HIRA of individuals diagnosed with HNC that underwent RT from January 2010 to December 2014. The institutional review board (IRB) of Dongguk University Gyeongju Hospital approved the study protocol (IRB no. 11075-201905-HR-0802).

The study subjects consisted of patients diagnosed with HNC according to the Korean Classification of Disease ( $6^{\text {th }}$ edition (KCD-6)), which is a version of the International Classification of Disease 10 (ICD-10) modified for the Korean health care system. Classifications of HNCs include lip (C00), base of tongue (BOT) (C01), other tongue regions (C02), gum (C03), floor of mouth (C04), palate (C05), other mouth regions (C06), parotid gland (C07), other salivary gland (C08), tonsil (C09), oropharynx (C10), nasopharynx (C11), pyriform sinus (C12), hypopharynx (C13), other oral cavity and pharynx (C14), nasal cavity and middle ear (C30), accessory sinuses (C31), and glottis (C32). Patients were identified using procedural codes. IS is represented as code I63.

Patients with distant metastasis or another cancer were excluded. Because the first end point of the present study was the risk of IS following carotid artery stenosis after RT, patients with IS diagnosed at time of diagnosis or during the 4 weeks following RT were excluded. The incidence of IS after RT was assessed up to the end of December 2018, and we evaluated the effects of age, sex, and surgery.

We also grouped subjects based on the receipt of frequent RT or less-frequent RT based on disease classification. BOT (C01), palate (C05), oropharynx (C10), nasopharynx (C11), pyriform sinus (C12), hypopharynx (C13), and supraglottis (C32.1) patients were allocated to group A, and all others were allocated to group 
B. The statistical analyses were performed using SAS version 9.3 (SAS Institute Inc., Cary, NC), and statistical significance was accepted for $\mathrm{p}$ values $<0.05$.

\section{RESULTS}

A total of 12,079 HNC patients that received RT between 2010 and 2014 were identified using HIRA claim data. Median age at diagnosis was 61 years, and 9401 patients were men and 2678 were women. Analysis of the cohort with respect to age and gender showed that males in their $50 \mathrm{~s}, 60 \mathrm{~s}$, or $70 \mathrm{~s}$ accounted for the majority of HNC patients (figure 1).

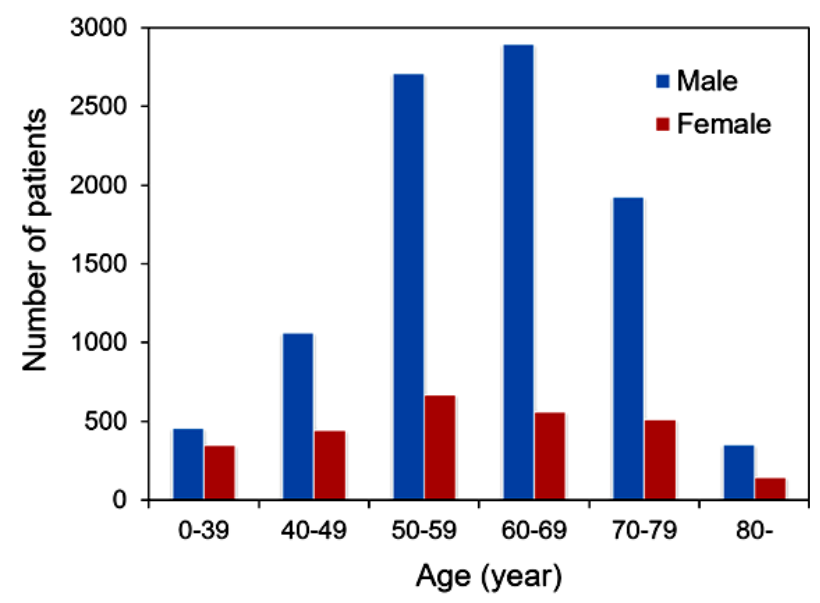

Figure 1. Overall distribution of head and neck cancer patients according to age and sex.

Glottic cancer was the most common disease classification $(n=1678)$, closely followed by nasopharyngeal cancer $(n=1660)$ and then by tonsil cancer $(n=1269) .472(3.9 \%)$ of the study subjects experienced IS, which had a prevalence of $>5 \%$ in hypopharyngeal cancer and supraglottic cancer. Nasopharyngeal cancer and oropharyngeal cancer had IS rates of $4.3 \%$ and $4.9 \%$, respectively, tongue cancer and BOT cancer had IS rates of $2.6 \%$ and $3.6 \%$, respectively, and glottic cancer and supraglottic cancer had IS rates of $4.4 \%$ and $5.6 \%$, respectively. The prevalences of IS by cancer type are sum marized in table 1.

The 472 patients that experienced IS had a median age of 66 years and median time from RT completion to IS was 35 months (table 2). Int. J. Radiat. Res., Vol. 19 No. 4, October 2021
The median age of patients that did not experience IS was 60 years. No peak time for IS occurrence after RT completion was observed, though its incidence tended to decrease gradually with time (figure 2).

Table 1. Incidences of ischemic stroke for different cancer types.

\begin{tabular}{|c|c|c|c|c|}
\hline & \begin{tabular}{c|} 
Total \\
patients, $\mathrm{n}$
\end{tabular} & $\begin{array}{c}\text { Male, } \\
\mathrm{n}\end{array}$ & $\begin{array}{c}\text { Female, } \\
\mathbf{n}\end{array}$ & $\begin{array}{c}\text { Stroke, n } \\
(\%)\end{array}$ \\
\hline Lip (CO0) & 36 & 20 & 16 & $2(5.6 \%)$ \\
\hline $\begin{array}{l}\text { Base of Tongue } \\
\text { (CO1) }\end{array}$ & 634 & 485 & 149 & 24 (3.8\%) \\
\hline Tongue (C02) & 984 & 646 & 338 & $26(2.6 \%)$ \\
\hline Gum (CO3) & 280 & 161 & 119 & $10(3.6 \%)$ \\
\hline $\begin{array}{l}\text { Floor of Mouth } \\
\text { (CO4) }\end{array}$ & 211 & 163 & 48 & $8(3.8 \%)$ \\
\hline Palate (C05) & 393 & 254 & 139 & $11(2.8 \%)$ \\
\hline Oral Cavity (C06) & 572 & 371 & 201 & $15(2.6 \%)$ \\
\hline Parotid (C07) & 877 & 503 & 374 & $29(3.3 \%)$ \\
\hline $\begin{array}{l}\text { Salivary Gland } \\
\text { (C08) }\end{array}$ & 464 & 272 & 192 & $14(3.0 \%)$ \\
\hline Tonsil (C09) & 1269 & 1082 & 187 & 45 (3.5\%) \\
\hline Oropharynx (C10) & 432 & 390 & 42 & $21(4.9 \%)$ \\
\hline $\begin{array}{l}\text { Nasopharynx } \\
\text { (C11) }\end{array}$ & 1660 & 1260 & 400 & 71 (4.3\%) \\
\hline $\begin{array}{l}\text { Pyriform Sinus } \\
\text { (C12) }\end{array}$ & 396 & 382 & 14 & $17(4.3 \%)$ \\
\hline $\begin{array}{l}\text { Hypopharynx } \\
\text { (C13) }\end{array}$ & 903 & 830 & 73 & 49 (5.4\%) \\
\hline Others (C14) & 66 & 52 & 14 & $1(1.5 \%)$ \\
\hline Nasal Cavity (C30) & 331 & 209 & 122 & $10(3.0 \%)$ \\
\hline $\begin{array}{c}\text { Accessory Sinus } \\
\text { (C31) }\end{array}$ & 407 & 283 & 124 & $18(4.4 \%)$ \\
\hline Glottis (C32) & 1678 & 1596 & 82 & 74 (4.4\%) \\
\hline $\begin{array}{l}\text { Supraglottis } \\
\text { (C32.1) }\end{array}$ & 486 & 442 & 44 & $27(5.6 \%)$ \\
\hline All & 12079 & 9401 & 2678 & $\begin{array}{c}472 \\
(3.9 \%)\end{array}$ \\
\hline
\end{tabular}

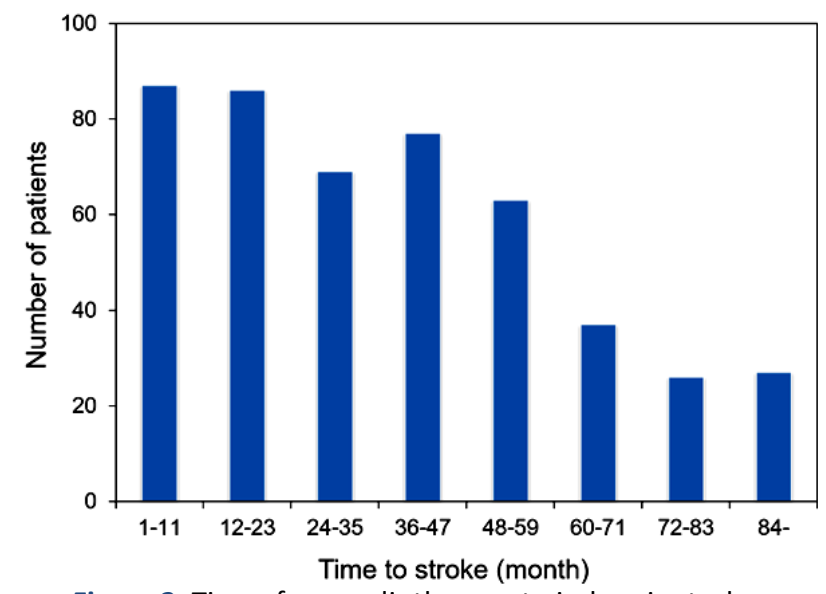

Figure 2. Times from radiotherapy to ischemic stroke. 
Table 2. Characteristics of patients that experienced ischemic stroke.

\begin{tabular}{|c|c|c|}
\hline & $\begin{array}{c}\text { Stroke } \\
(\mathbf{n = 4 7 2})\end{array}$ & $\begin{array}{c}\text { Non-stroke } \\
(\mathbf{n = 1 1 6 0 7 )}\end{array}$ \\
\hline Age (year) & & \\
\hline Mean & 64.93 & 59.58 \\
\hline Median & 66 & 60 \\
\hline SD & 9.72 & 12.98 \\
\hline Time to stroke (month) & & \\
\hline Mean & 36.63 & \\
\hline Median & 35 & \\
\hline SD & 24.98 & \\
\hline
\end{tabular}

SD: Standard Deviation

We also investigated the effects of risk factors, such as, irradiated field and some patient factors, on stroke incidence. Age was the most important risk factor for IS. The incidence of IS was $5.4 \%$ in patients $>60$, but $2.2 \%$ in patients $<60$ years (relative risk (RR) 2.59). Group A had a higher risk of IS than group B (4.5\% vs $3.5 \%$, RR 1.29 ), and men had a higher incidence than women (4.1\% vs 3.1\%, RR 1.33 ). All the above results were significant; details are provided in table 3.

Table 3. Relative risk for ischemic stroke according to irradiation field, sex, age, and operation in patients with head and neck cancer that underwent radiotherapy.

\begin{tabular}{|c|c|c|c|c|c|}
\hline & $\begin{array}{l}\text { Total pa- } \\
\text { tients, } n\end{array}$ & $\begin{array}{c}\text { Stroke, } \mathrm{n} \\
(\%)\end{array}$ & RR & $95 \% \mathrm{Cl}$ & p-value \\
\hline \multicolumn{6}{|l|}{ Neck } \\
\hline Group A & 4904 & $\begin{array}{c}220 \\
(4.5 \%)\end{array}$ & 1.290 & $\begin{array}{c}1.073- \\
1.552\end{array}$ & 0.007 \\
\hline Group B & 7175 & $\begin{array}{c}252 \\
(3.5 \%)\end{array}$ & 1 & & \\
\hline \multicolumn{6}{|l|}{ Sex } \\
\hline Male & 9401 & $\begin{array}{c}388 \\
(4.1 \%)\end{array}$ & 1.329 & $\begin{array}{c}1.046- \\
1.690 \\
\end{array}$ & 0.020 \\
\hline Female & 2678 & $84(3.1 \%)$ & 1 & & \\
\hline \multicolumn{6}{|l|}{ Age } \\
\hline$\geq 60$ & 6390 & $\begin{array}{c}348 \\
(5.4 \%)\end{array}$ & 2.585 & $\begin{array}{c}2.099- \\
3.183\end{array}$ & $<0.001$ \\
\hline$<60$ & 5689 & $\begin{array}{c}124 \\
(2.2 \%)\end{array}$ & 1 & & \\
\hline \multicolumn{6}{|l|}{ Operation } \\
\hline With & 9943 & $\begin{array}{c}393 \\
(4.0 \%)\end{array}$ & 1.072 & $\begin{array}{c}0.838- \\
1.371\end{array}$ & 0.583 \\
\hline Without & 2136 & 79 (3.7\%) & 1 & & \\
\hline
\end{tabular}

RR: Relative Risk, Cl: Confidence Interval

\section{DISCUSSION}

According to the National Cancer Control Institute's annual report of cancer statics in 2017, of 214,701 cancer patients in South Korea in 2015, the number of HNC cases (excluding thyroid cancer cases) was 4455(23). Thus, HNC accounted for $2.1 \%$ of all cancers, which is a relatively small number, though numbers have increased continuously over recent years. Little research has been conducted on the risk of IS in HNC patients, and the majority of studies on the topic have compared RT and non-RT treated

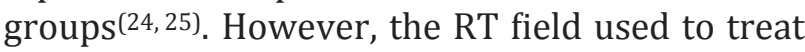
HNC varies with cancer site, type, and stage. Thus, we classified patients that received RT into two groups according to RT field size. Since information on RT fields could not be obtained, cancers that normally undergo elective neck irradiation were allocated to group A. Because the palate is treated using different $\mathrm{RT}$ ranges according to whether the soft or hard palate is affected, cases of palate cancer were allocated to group A.

In the present study, patients in group A had a higher incidence of IS than patients in group B. This may have been because carotid blood vessels in both sides of necks were exposed to RT ( $4.5 \%$ vs $3.5 \%$, p=0.007). When we compared the risk of IS for glottic and supraglottic cancer, we found supraglottic cancer had a 20\% higher risk (absolute risk 4.4\% vs 5.6\%). Presumably, because supraglottic cancer is more prone to neck node metastases than glottis cancer, and thus, both sides of the neck were included in RT fields(26). Furthermore, the higher prevalence of IS observed for glottis cancer than other cancers may be related to its better prognosis, and hence a greater number of survivors .

Stroke is heterogeneous, multifactorial disease, and understanding of its risk factors is important for treatment and prevention. Risk factors can be categorized as modifiable or nonmodifiable factors. Nonmodifiable risk factors include age, sex, race-ethnicity, and genetics, whereas hypertension, diabetes mellitus, arrhythmia, smoking, diet, and physical activity are commonly reported modifiable risk factors ${ }^{27}$ -29). Of these nonmodifiable factors, advanced age

Int. J. Radiat. Res., Vol. 19 No. 4, October 2021 
is the most important risk factors. 95\% of strokes occur in subjects aged $\geq 45$ years and two-thirds of strokes occurred in subjects aged $\geq 65$. Furthermore, men, especially middle-aged to elderly men, have a slightly higher risk of stroke than women. In the present study, we found higher rates of stroke among aged $>60$ years and among men.

Radiation has been shown to be an independent risk factor of cardiovascular and cerebrovascular disease in cancer patients $(30,31)$. Post radiation vasculopathy occurs in intra and/ or extracranial vessels, and medium and large sized vessels are most frequently damaged. Radiation to the neck has been related to subsequent vascular wall thickening, atherosclerotic plaque formation, and vascular damage ${ }^{(6)}$. Previous studies have demonstrated that RT predisposes the formation of inflammatory plaque, which is more prone to rupture and cause IS. Patients that have received RT in the neck area have also been shown to have significant greater risks of internal carotid artery (ICA) and common carotid artery (CCA) stenosis. The risk of ischemic stroke probably depends on the severity of ICA stenosis. Reported frequencies of ICA stenosis following neck-RT range from 12 to $60 \%$. The first large-scale report was conducted in 1981 and demonstrated a post-cervical RT stroke incidence of $6.3 \%$ (32). Scott et al. reported a crude stroke rate of $2.6 \%$ following neck RT as compared with $0.29 \%$ for non-RT patients (33). On the other hand, in three large-scale studies, radiation fields that included the carotid artery did not seem to increase the risk of stroke in breast cancer survivors ${ }^{(34-36)}$.

Our analysis of time to IS occurrence by year revealed similar risks per year and no peak time. The decrease in patient numbers observed per annum was simply attributed to reduced survivals. This finding of similar risks per year also suggests that the risk of radiation-induced IS is not significant, which ostensibly contradicts our finding of a significantly higher risk of IS due to radiation exposure of whole neck, but we emphasize that this increase in risk was only $1 \%$. Nevertheless, despite this slight increase in absolute IS risk for whole neck RT, it is worth considering regular follow-up and prophylactic medications, such as aspirin and statin, for IS when whole neck irradiation is performed in older patients.

Since our study is a study using insurance claims data, the number of patients was large but it was not possible to obtain detail information of patients. Various risk factors, such as smoking and alcohol, related to IS could not be analyzed. The specific information about RT could not be obtained, too. Although accurate analysis is difficult, it is judged that it is possible to grasp the trend according to the number of patients. And, most institutions in South Korea have treated HNC patients with intensity modulated radiotherapy (IMRT) since 2010, and neck vessel must be included in the RT field to cover lymph nodes chains. So, we thought that the difference according to the radiation delivery technique, such as 3-dimensional conformal RT and IMRT, will be small. And, our inability to confirm patient death is a limitation of the present study. Therefore, comparisons of risk factors are considered more valuable than absolute incidences. Because glottis cancer has a relatively good survival rate, it is likely that IS incidence rates increased despite not being an indication of elective both neck irradiation. Nasopharyngeal cancer, hypopharyngeal cancer, and oropharyngeal cancer are representative HNC indicators for elective whole neck irradiation and relatively poor survival, and all of these carcinomas have above average IS incidence rates, which suggests much regarding the relationship between neck irradiation and IS. The present study shows the rate of ischemic stroke was increased significantly by whole neck irradiation, but that this increase was small. Nevertheless, when performing extensive radiotherapy of whole neck in older male patients, close follow-up and prophylactic medication should be considered to reduce the risk of ischemic stroke.

Certificate number of local institutional review board: 11075-201905-HR-08-02.

\section{Conflicts of interest: Declared none.}




\section{REFERENCES}

1. Siegel RL, Miller KD, Jemal A (2019) Cancer statistics, 2019. CA Cancer J Clin, 69(1): 7-34.

2. Rettig EM, D'Souza G (2015) Epidemiology of Head and Neck Cancer. Surg Oncol Clin N Am, 24(3): 379-396.

3. Vigneswaran N, Williams MD (2014) Epidemiologic trends in head and neck cancer and aids in diagnosis. Oral and Maxillofacial Surgery Clinics of North America, 26(2): 123141.

4. Kjems J, Gothelf AB, Hakansson K, Specht L, Kristensen CA, Friborg J (2016) Elective nodal irradiation and patterns of failure in head and neck cancer after primary radiation therapy. Int J Radiat Oncol Biol Phys, 94(4): 775-782.

5. van den Bosch S, Dijkema T, Verhoef LC, Zwijnenburg EM, Janssens GO, Kaanders JH (2016) Patterns of recurrence in electively irradiated lymph node regions after definitive accelerated intensity modulated radiation therapy for head and neck squamous cell carcinoma. Int J Radiat Oncol Biol Phys, 94(4): 766-774.

6. Carpenter DJ, Mowery YM, Broadwater G, Rodrigues A, Wisdom AJ, Dorth JA, Patel PR, Shortell CK, Clough R, Brizel DM (2018) The risk of carotid stenosis in head and neck cancer patients after radiation therapy. Oral Oncol, 80: 9-15.

7. Bianchini Massoni C, Gargiulo M, Pini R, Faggioli G, Marcucci V, Freyrie A, Vasuri F, Pasquinelli G, Stella A (2017) Radiation-induced carotid stenosis: Perioperative and late complications of surgical and endovascular treatment. $J$ Cardiovasc Surg (Torino), 58(5): 680-688.

8. Baselet B, Rombouts C, Benotmane AM, Baatout S, Aerts A (2016) Cardiovascular Diseases Related to Ionizing Radiation: The Risk of Low-Dose Exposure (Review). International Journal of Molecular Medicine, 38(6): 1623-1641.

9. Sharma NK, Sharma R, Mathur D, Sharad S, Minhas G, Bhatia K, Anand A, Ghosh SP (2018) Role of ionizing radiation in neurodegenerative diseases. Frontiers in aging neuroscience, 10: 134-134.

10. Huang R, Zhou Y, Hu S, Ren G, Cui F, Zhou P-K (2019) Radiotherapy exposure in cancer patients and subsequent risk of stroke: A systematic review and meta-analysis. Frontiers in Neurology, 10(233).

11. Dorresteijn L, Kappelle A, Boogerd W, Klokman W, Balm A, Keus R, Leeuwen F, Bartelink H (2002) Increased Risk of Ischemic Stroke after Radiotherapy on the Neck in Patients Younger Than 60 Years. Official Journal of the American Society of Clinical Oncology; Journal of clinical oncology, 20: $282-288$.

12. Gassmann A (1899) Zur Histologie Der Roentgenulcera. Fortschr Geb Roentgenstr, 2(199): 1899-1207.

13. Gold H (1961) Production of arteriosclerosis in the rat: Effect of X-Ray and a high-fat diet. Arch Pathol, 71: 268273.

14. Lindsay S, Entenman C, Ellis EE, Geraci CL (1962) Aortic Arteriosclerosis in the Dog after Localized Aortic Irradiation with Electrons. Circulation Research, 10(1): 61-67.

15. Weintraub NL, Jones WK, Manka D (2010) Understanding radiation-induced vascular disease. Journal of the American College of Cardiology, 55(12): 1237-1239.

16. Murros KE and Toole JF (1989) The Effect of Radiation on Carotid Arteries: A Review Article. Archives of Neurology, 46(4): 449-455.

17. Yoshii Y (2008) Pathological Review of Late Cerebral Radionecrosis. Brain Tumor Pathology, 25(2): 51.
18. Fajardo L (1999) Is the Pathology of Radiation Injury Different in Small Vs Large Blood Vessels? Cardiovascular Radiation Medicine, 1(1): 108.

19. Flaherty ML, Kissela B, Khoury JC, Alwell K, Moomaw CJ, Woo D, Khatri P, Ferioli S, Adeoye O, Broderick JP, Kleindorfer D (2013) Carotid Artery Stenosis as a Cause of Stroke. Neuroepidemiology, 40(1): 36-41.

20. Villwock MR, Padalino DJ, Deshaies EM (2015) Carotid Artery Stenosis with Acute Ischemic Stroke: Stenting Versus Angioplasty. Journal of Vascular and Interventional Neurology, 8(4): 11-16.

21. Zhu CZ and Norris JW (1990) Role of Carotid Stenosis in Ischemic Stroke. Stroke, 21(8): 1131-1134.

22. Bashar K, Healy D, Clarke-Moloney M, Burke P, Kavanagh E, Walsh S-R (2014) Effects of Neck Radiation Therapy on Extra-Cranial Carotid Arteries Atherosclerosis Disease Prevalence: Systematic Review and a Meta-Analysis. PloS one, 9(10): e110389-e110389.

23. Jung KW, Won YJ, Kong HJ, Lee ES, Community of Population-Based Regional Cancer R (2018) Cancer Statistics in Korea: Incidence, Mortality, Survival, and Prevalence in 2015. Cancer Res Treat, 50(2): 303-316.

24. Arthurs E, Hanna TP, Zaza K, Peng Y, Hall SF (2016) Stroke after Radiation Therapy for Head and Neck Cancer: What Is the Risk? Int J Radiat Oncol Biol Phys, 96(3): 589-596.

25. Chu CN, Chen SW, Bai LY, Mou CH, Hsu CY, Sung FC (2011) Increase in Stroke Risk in Patients with Head and Neck Cancer: A Retrospective Cohort Study. Br J Cancer, 105(9): 1419-1423.

26. Tachibana $T$, Orita $Y$, Marunaka $H$, Makihara $S I$, Hirai $M$, Gion Y, Ikegami K, Miki K, Makino T, Noyama Y, Komatsubara Y, Kimura M, Yoshino T, Nishizaki K, Sato Y (2018) Neck Metastasis in Patients with T1-2 Supraglottic Cancer. Auris Nasus Larynx, 45(3): 540-545.

27. Hillen $T$, Coshall $C$, Tilling $K$, Rudd AG, McGovern R, Wolfe CDA (2003) Cause of Stroke Recurrence Is Multifactorial. Stroke, 34(6): 1457-1463.

28. Boehme AK, Esenwa C, Elkind MSV (2017) Stroke Risk Factors, Genetics, and Prevention. Circulation Research, 120 (3): 472-495.

29. Allen CL and Bayraktutan U (2008) Risk Factors for Ischaemic Stroke. Int J Stroke, 3(2): 105-116.

30. Marmagkiolis K, Finch W, Tsitlakidou D, Josephs T, Iliescu C, Best JF, Yang EH (2016) Radiation Toxicity to the Cardiovascular System. Curr Oncol Rep, 18(3): 15.

31. Tanguturi SK and Alexander BM (2018) Neurologic Complications of Radiation Therapy. Neurol Clin, 36(3): 599-625.

32. Elerding SC, Fernandez RN, Grotta JC, Lindberg RD, Causay LC, McMurtrey MJ (1981) Carotid Artery Disease Following External Cervical Irradiation. Ann Surg, 194(5): 609-615.

33. Scott AS, Parr LA, Johnstone PA (2009) Risk of Cerebrovascular Events after Neck and Supraclavicular Radiotherapy: A Systematic Review. Radiother Oncol, 90(2): 163-165.

34. Jagsi R, Griffith KA, Koelling T, Roberts R, Pierce LJ (2006) Stroke Rates and Risk Factors in Patients Treated with Radiation Therapy for Early-Stage Breast Cancer. J Clin Oncol, 24(18): 2779-2785.

35. Selvik HA, Thomassen L, Logallo N, Naess H (2014) Prior Cancer in Patients with Ischemic Stroke: The Bergen Norstroke Study. J Stroke Cerebrovasc Dis, 23(5): 919-925.

36. Woodward WA, Giordano SH, Duan Z, Hortobagyi GN, Buchholz TA (2006) Supraclavicular Radiation for Breast Cancer Does Not Increase the 10-Year Risk of Stroke. Cancer, 106(12): 2556-2562. 